\title{
A 3-Transistor Low Power Rectifier for Wideband RF Energy Harvesting with a Threshold Voltage Compensation Technique using 45 nm Technology
}

\author{
${ }^{1}$ MANASH PRATIM SARMA, ${ }^{2}$ KANDARPA KUMAR SARMA \\ ${ }^{1,2}$ Department of Electronics and Communication Engineering \\ ${ }^{1,2}$ Gauahati University, Assam, INDIA
}

\begin{abstract}
With the advent of modern wireless communication technology and increasing requirement of high speed network, network life-time is becoming a major area of concern. The need of network power management is gaining attention with the high data network in place and is making a paradigm shift towards green communication. Hence embedding the RF energy harvesting (EH) capability in a wireless net work is becoming inevitable. To make RF EH a reality a hi gh frequency rectifier is indeed indispensable along with other circuits in the system. The RF energy needs to be harvested from the available sources in the ambience. It is also seen that the current generation of RF sourc es radiates at a very low s ignal power. So, to successfully convert and store this energ $\mathrm{y}$, the rectifier must not only be able to provi de a sufficiently higher percentage conversion ratio (PCE) but also be able to cater it at a lower $r$ ange of signal power. This paper presents the design and analy sis of a sim plified 3-transistor high frequency rectifier. A threshold voltage compensation technique is also incorporated and it a chieves a PCE upto $85 \%$ at $-2 \mathrm{dBm}$ in its single stage im plementation. This is observed to be one of the highest in-class efficiency as compared to recently reported designs. From the frequency response it is seen to exhibit wide band performance spanning almost all popular wireless bands. The dynamic power dissipation (DPD) is calculated to be $6.25 \mathrm{pW}$ at $-2 \mathrm{~dB}$, whereas the leakage power (LP) is
\end{abstract} observed to be zero.

Key-Words: -Energy Harvesting, PCE, Transmission Gate, Dynamic Power Dissipation, Leakage Power

Received: November 2, 2019. Revised: March 8, 2020. Accepted: April 1, 2020. Published: April 17, 2020.

\section{Introduction}

Modern wireless co mmunication is able to cater the need of $h$ igh speed data network. Also the demand for higher data rate an $d$ seamless connectivity is ever increasing. But with the enhancement of data rate, communication networks tend to become power hungr y. Also to successfully install a wireless network in a hard to reach location, power turns out $\mathrm{t} o$ be $\mathrm{t}$ he main concern. Hence power management and network li fe-time are becoming a major area $\mathrm{s}$ to be explored. Energy harvesting $(\mathrm{EH})$ is a pri mary focus area in all such upcoming communication networks. It enables th e network to become self-sustaining in physical and virtual modes [1]. Lately, artificial means are receiving greater importance in providing support towards energy harvesting applications. In this regard, network topol ogy, deployment and device design play important roles [1][2][3]. RF EH is a major domain in EH fiel $\mathrm{d}$ as multiple RF sources are available in the ambience for harvesting.

An EH de sign is for med by a rectifier or a charge pump. Several des ign challenges are $f$ aced while designing such a rectifier. Such challenges are identified as high frequency compatibility, low power dissipation, lesser silicon area etc. But the enhancement of the pow er conversion efficiency (PCE) at lower input $\mathrm{p}$ ower is the most important criteria which the designer must address while formulating an efficient circuit design. A Cross coupled bridge rectifier with differential RF input is reported that provides lo $\mathrm{w}$ on state current and negligible leakage current and th us offers a better PCE[4]. An Ultra High Frequency (UHF) rectification unit based on voltage doubler is also designed with the techni que of inter nal voltage cancellation to facilitate a zero-threshold transistor. They have claimed to achieve a good with reduced area [5]. A very widely used structure in EH is the 
Dickson charge pump. Several modifications to the basic structure have be en proposed by several designers for specific applications achieving different efficiencies. The Dickson charge pump has been modified to reduce the leakage current with linear regulator and thereby total po wer consumption can be reduced [ 6]. Another Dickson charge pump based $r$ ectifier with improved performance in two configurations a re presented which works in GSM band with a satisfactory PCE [7]. Also dynam ic threshold reduction technique based CMOS rectifier has been designed with the use of a clamper to redu ce the effective threshold voltage and increase the sensitivity and hence achieving a high PCE [8]. A coplanar waveguide based compact RF r ectifier has b een proposed in [9], which claims to achieve a peak PCE of $74.8 \%$ at $10 \mathrm{dBm}$ in the frequency range of 0.1 to $2.5 \mathrm{GHz}$. The structure is cascaded to get a higher output voltage. A low tem perature coefficient bandgap voltage reference along with a high efficiency rectifier is reported in [ 10]. A curvature compensation technique is also propos ed and the final PCE of $87.2 \%$ is achieved.A low power CMOS full bridge rectifier with four transistors at $130 \mathrm{~nm}$ technology is presented in [ 11]. An AC-DC rectifier, an impedance matching network and a DCDC converter with maximum power point tracking system is de signed which is observed to attain a peak efficiency of $5 \%$.

This paper presents the design and analysis of a simplified 3-transistor high frequency rectifier. A threshold voltage co mpensation technique is also incorporated and it achieves a P CE upto $85 \%$ at $2 \mathrm{dBm}$ in its single stage im plementation. This is observed to be one of the highest in-class effici ency as compared to recently reported designs. Fro $m$ the frequency response it is seen to exhibit wide band performance spanning almost all popular wirel ess bands. The $d$ ynamic power dissipation (DPD) is calculated to be $6.25 \mathrm{pW}$ at $-2 \mathrm{~dB}$, whereas the leakage power (LP) is observed to be zero.

The remaining of the paper is organized as follows. Section II deals with the proposed design with explanation of $t$ he functionality, Section III deals with $\mathrm{s}$ imulation results and discussion and Section IV includes the concluding remark.

\section{Proposed Threshold Voltage Compensated 3-Transistor High Frequency Rectifier}

The basic unit of a RF EH consists of a matching unit, a rectifier and a power management unit. This paper is exploring a successful desig $\mathrm{n}$ of a high frequency rectifier. While designing a rectifier the main challenge is to make the circuit work at a lo $\mathrm{w}$ input power. The circuit is subjected to a vary ing low power signal and wh en the input voltage falls below threshold $\mathrm{v}$ oltage value of the nMOS, the rectification from the positive cy cle stops.

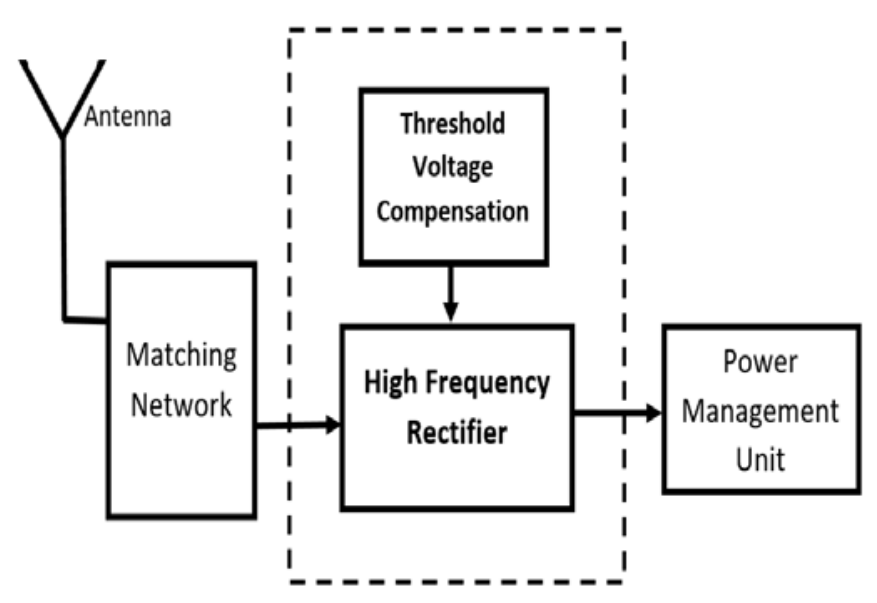

Figure 1: The Block diagram of Proposed RF EH system

Similarly in the negative cy cle when the input voltage exceeds the threshold voltage of the pMOS, the rectification cannot happen. This makes the circuit to suffer in term s of the PCE. Hence some threshold voltage compensation $t$ echnique is required. This will increase the ti me duration of rectification and thereby contribute towards the betterment of the PCE. The basic block diagram of the proposed system is shown in Fig. 1.

The concept of the proposed design is derived by observing the characteristics of a transmission gate (TG). The TG is a known technology and it finds its application in many CMOS based circuits. It is established that the nMOS pass transistor can pass the negative logic successfully with less propagation time. Again the pMOS pass transistor is known for efficient transfer of positive logi $c$ at 1 ess propagation time. This makes the TG a well suited candidate for such situations where the circuit needs to deal with bot $\mathrm{h}$ the voltage le vels. Another important aspect of TG is that it can generate a sufficiently higher on state current for both the input 
levels. This feature is attractive as far as the rectifier design is concerned.

The proposed design of rectifier pr esented here is a simplified version of the TG based rectifier reported in [12]. The circuit is desig ned to work with a randomly varying input signal. As the input voltage remains in the po sitive cycle, the nMOS, which is diode connected will be $\mathrm{ON}$ and the T G will allow the current to flow through. When the input goes negative the pMOS in the TG, which is also diode $\mathrm{c}$ onnected makes an open path for the current to flow. The current generated in both the cycles of operation will flow through the diode connected nMOS at the output stage, which is responsible for making the current flow to the output capacitor unidirectional. Thus $t$ he rectified output voltage is appeared across the capacitor. But it is observe $d$ that $t$ he output generated yields a lower PCE than that expected. This is due to the fact that the transistors enter the cut-off states a $\mathrm{s}$ the value of the RF input sig nal falls below threshold voltage value of the re spective transistor. This makes a threshold voltage compensation technique necessary. This paper proposes a very simple threshold voltage compensation technique with the use of a capacitor at the ga te of each transistors as shown in Fig. 2. The capacitor gets charged and retain some charge at every cycle. When the RF input voltage falls belo $\mathrm{w}$ a certain level, the transistor gets a voltage backing at lea st for so me time duration. As the negative terminal of the capacitor connected to the gate of the pMOS, it prevents the pMOS to go to cut-off for some ti me even when the RF input voltage exceeds the pMOS threshold voltage. This will effectively compensate the threshold voltage and allow the circuit to operate at a wider time period which will in turn enhance the output current and thus the PCE. The proposed 3 -transistor rectifier is shown in Fig. 2.

Let us consider the input $R F$ voltage be $V_{\text {in }}(t)$, the capacitance connected to the gate of the nMOS be $\mathrm{C}_{\mathrm{c}}$ and total resistance at the charging path be $\mathrm{R}_{\mathrm{c}}$. When the input voltage is high the capacitor gets charged and the voltage developed across the capacitor shall be $\mathrm{V}_{\mathrm{c}}=\mathrm{V}_{\text {in }}(\mathrm{t})\left[1-\mathrm{e}^{-\mathrm{t} / \mathrm{RcC} c}\right]$

When the input voltage $\mathrm{V}$ in $(\mathrm{t})$ falls to a low value, the voltage $\mathrm{V}_{c}$ appeared at the nMOS gate and thereby maintains a sufficiently higher value until it gets discharged below the threshold voltage value. Similarly, in the negative cycle, it protects the pMOS to gets off until the negative voltage exceeds the threshold voltage value. This is a si mple way by which we can extend the time of the rectification process and thereby enhance the PCE.

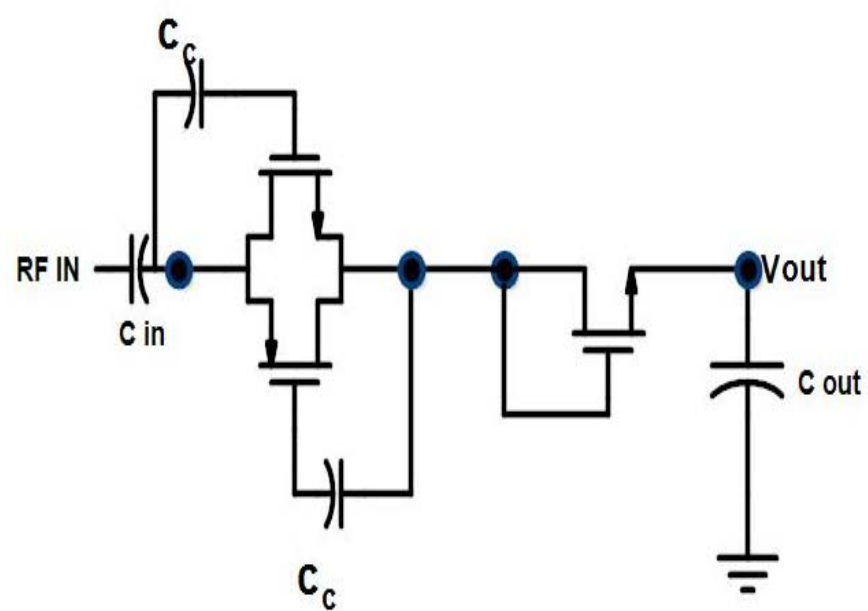

Figure 2: Proposed 3-transitor rectifier with threshold voltage compensation

In a TG structure when input is positi ve; the pMOS will be initially saturated and then shall switch to non-saturation state while the nMOS will be in saturation state. If we consider the $\mathrm{I}_{\mathrm{Dn}}$ and $\mathrm{I}_{\mathrm{Dp}}$ be the current through the nMOS and the pMOS of the TG respectively and $\mathrm{V}(\mathrm{t})$ be the RF signal voltage, also $I_{D o}$ be the current through the nMOS of the outpu $t$ stage then the total output current is

$\mathrm{I}_{\mathrm{D} o}=\mathrm{I}_{\mathrm{Dn}}$ for positive cycle and $\mathrm{I} \mathrm{Do}_{\mathrm{o}}=\mathrm{I}_{\mathrm{Dp}}$ for the negative cycle of the operation

As described in [12], the PCE can be calculated as $\mathrm{PCE}=\left(\mathrm{P}_{\text {out }} / \mathrm{P}_{\text {in }}\right) * 100 \%$

Here the $I_{D n}$ and $I_{D p}$ will increase due to the enhancement of rectification time period which will further increase $\mathrm{I}_{\mathrm{Do}}$. This makes the charging current at the $\mathrm{C}_{\text {out }}$ to rise and a higher $\mathrm{P}$ out can be obtained. This will lead to the enhancement of PCE. Hence the threshold voltage co mpensation technique is significant.

\section{Results and Discussion}

In this sect ion, the results obtained fro $m$ the experiments are presented and discussed.

Transistor sizing and aspect ratio is a very important aspect in the design for better performance. By using the optimization techniques as reported in [12] the aspect ratio of both the nMOS and the pMOS are tailored as follows. The optimization is done to ensure an optimum power dissipation. 


\section{Table 1: Aspect Ratios of both nMOS and pMOS devices}

\begin{tabular}{|c|c|c|c|}
\hline $\mathrm{L}_{\mathrm{n}}$ & $\mathrm{W}_{\mathrm{n}}$ & $\mathrm{L}_{\mathrm{p}}$ & $\mathrm{W}_{\mathrm{p}}$ \\
\hline $45 \mathrm{~nm}$ & $150 \mathrm{~nm}$ & $65 \mathrm{~nm}$ & $150 \mathrm{~nm}$ \\
\hline
\end{tabular}

The proper rectification a nd the lev el of the output DC voltage can be validated by observing the transient response. The transient resp onse of the circuit is done at $2 \mathrm{~dB}$ is shown in Fig. 3. The output voltage observed is $823 \mathrm{mV}$ at $2 \mathrm{~dB}$ input power with threshold voltage compensation.

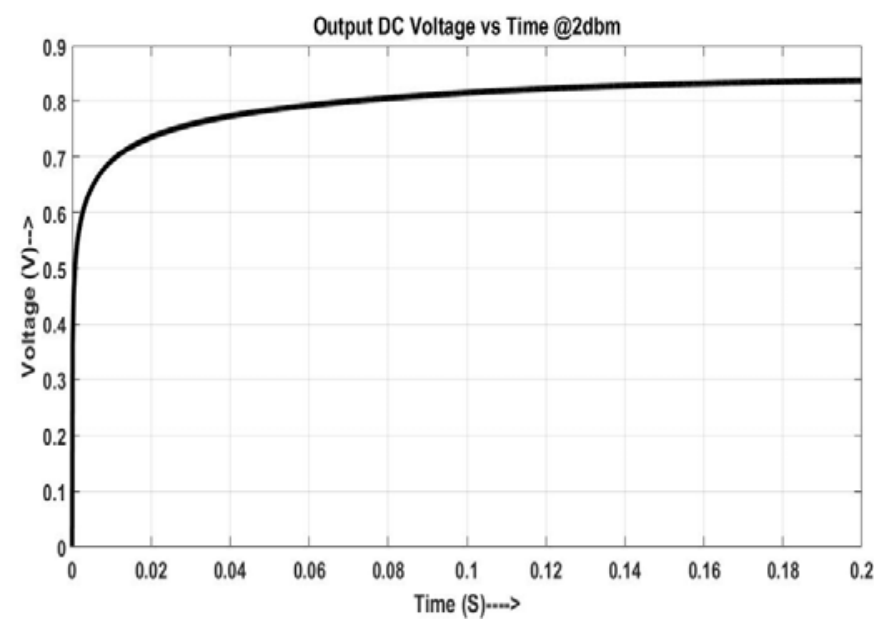

Figure 3: Output Transient DC Voltage

The output voltage and current values are dependent on the circuit components like $\mathrm{C}_{\text {in }}$ and $\mathrm{C}_{\text {out }}$ and the performance of the circuit with respect to these valyes needs to be studied. The DC output voltages and currents obtained are plotted with a range input capacitance. Both the ou tput voltage and output current are seen to show a decline with the increase in the value of input capacitances. This is depicted in Fig. 4

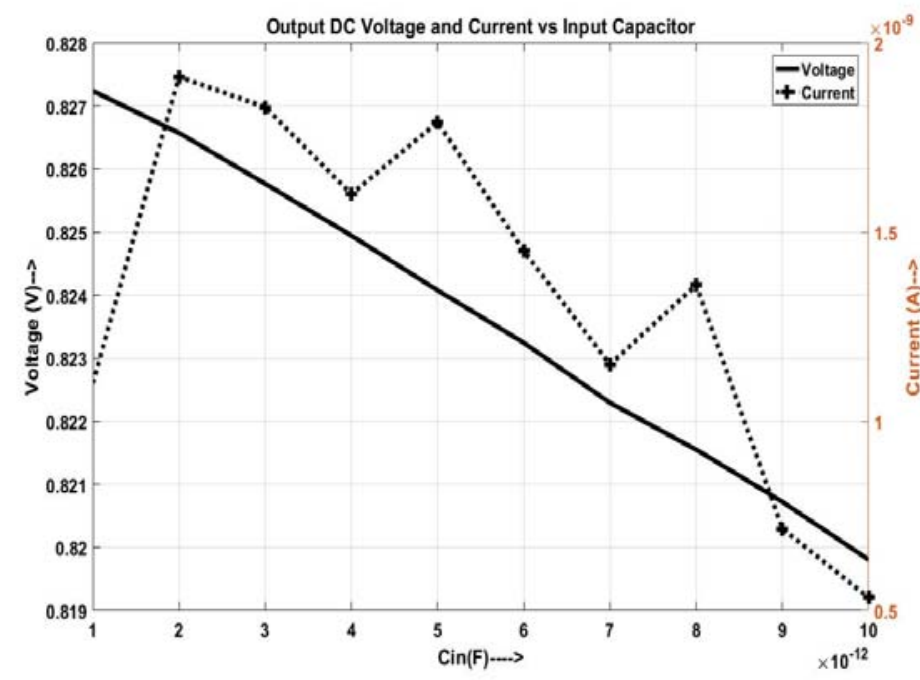

Figure 4: Output DC voltage and current vs $C_{\text {in }}$
The DC output voltage and current are plotted with different value of the output capacitan ce which is shown in Fig. 5. The voltage value sho ws a gradual decline whereas and current shows almost steady value with the increase in output capacitance.

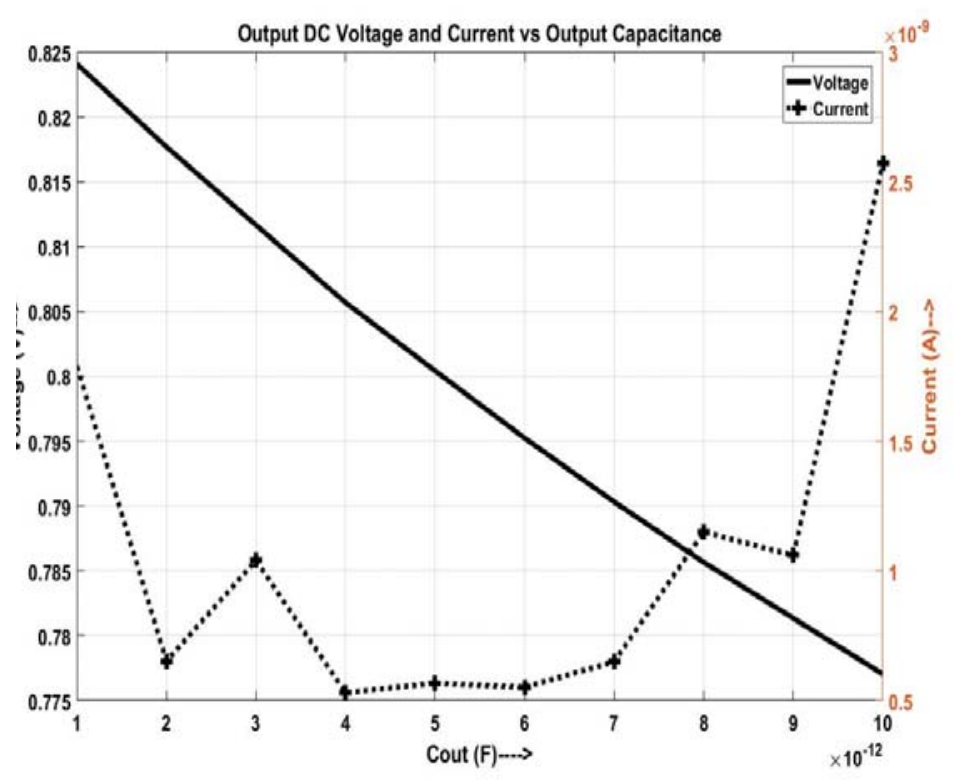

Figure 5: Output DC voltage and current vs $C_{\text {out }}$

As the sizing of the both the nMOS and pMOS will have an impact on the output, hence th e output DC voltage and current value are plotted across length and width of both the devices. This is shown in Figs. $6,7,8$ and 9 .

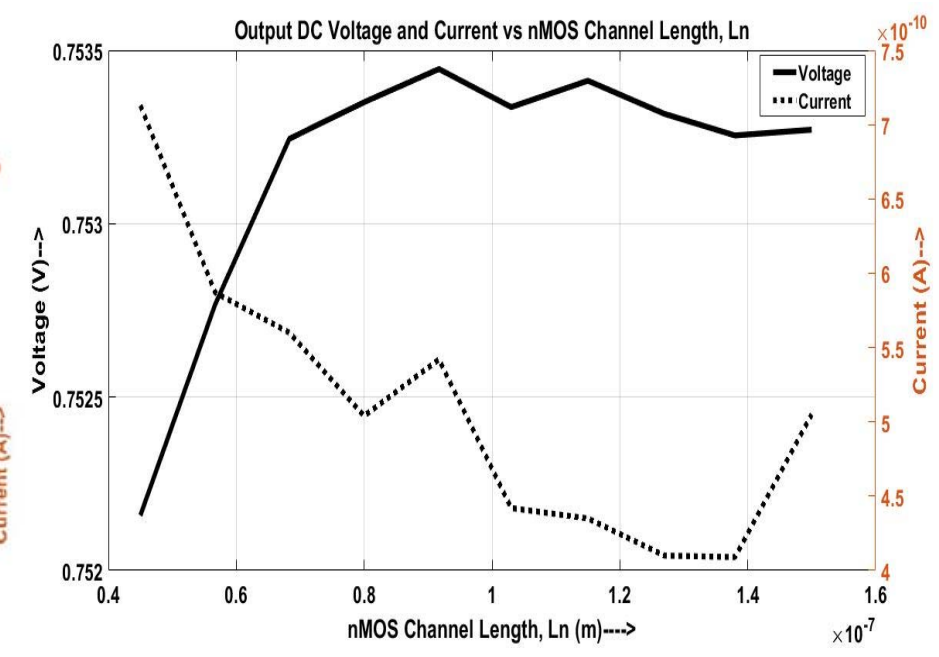

Figure 6: Output DC voltage and current vs $L_{n}$

Fig. 6 shown the output voltage and current wih respect to the nMOS channel length $\left(\mathrm{L}_{\mathrm{n}}\right)$. Here the DC voltage is seen to increase while the current is in decline. This is expected as more channel length 
increases channel resistance and decreases the current value. Similarly the output DC voltage and current is plotted across the nMOS width $\left(\mathrm{W}_{\mathrm{n}}\right)$. Both the voltage and the current is seen to i ncrease with the width. As broadening the device channel draws more current hence this nature is reflected here.

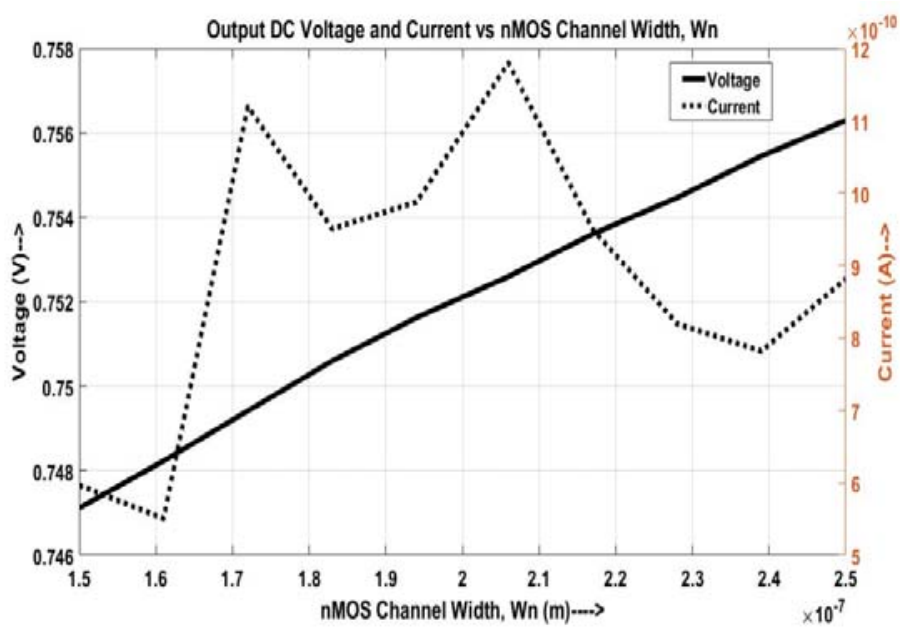

Figure 7: Output DC voltage and current vs $\mathbf{W}_{\mathbf{n}}$

The change in the output DC voltage and current across the $\mathrm{p}$ MOS channel length $\left(\mathrm{L}_{\mathrm{p}}\right)$ and channel width $\left(\mathrm{W}_{\mathrm{p}}\right)$ is depicted in Figs. 8 and 9. The DC voltage increases but the current decreases with $\mathrm{L}_{\mathrm{p}}$. While both the DC voltage and current increases with $\mathrm{W}_{\mathrm{p}}$.

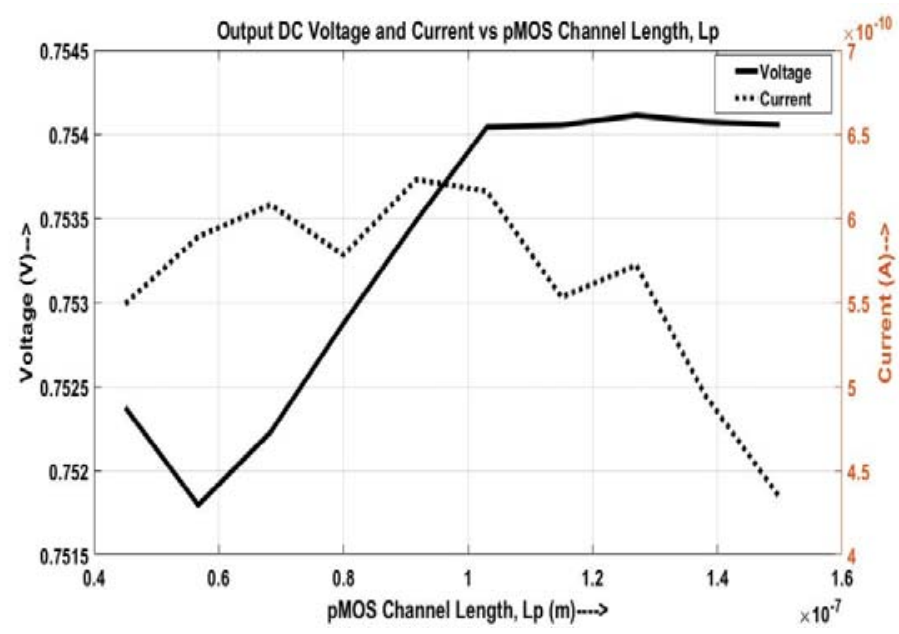

Figure 8: Output DC voltage and current vs $L_{p}$

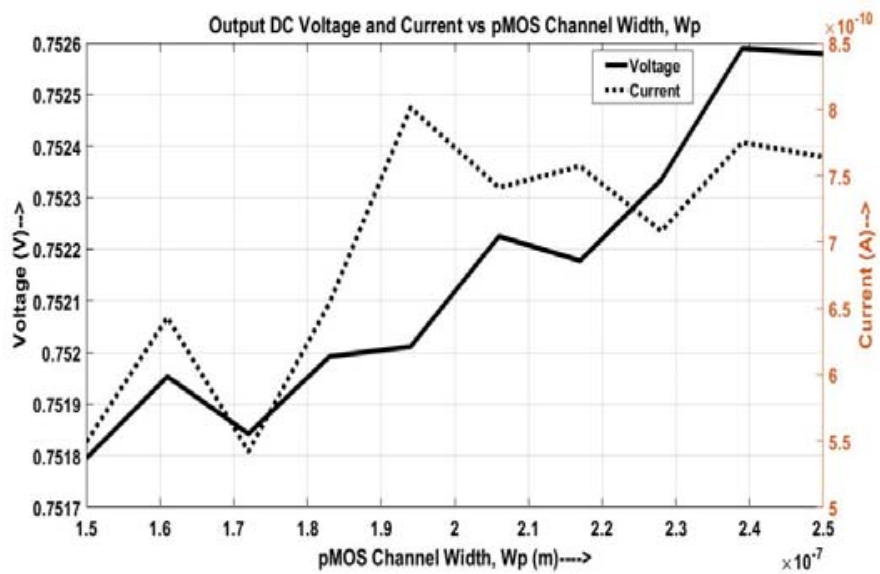

Figure 9: Output DC voltage and current vs $W_{p}$

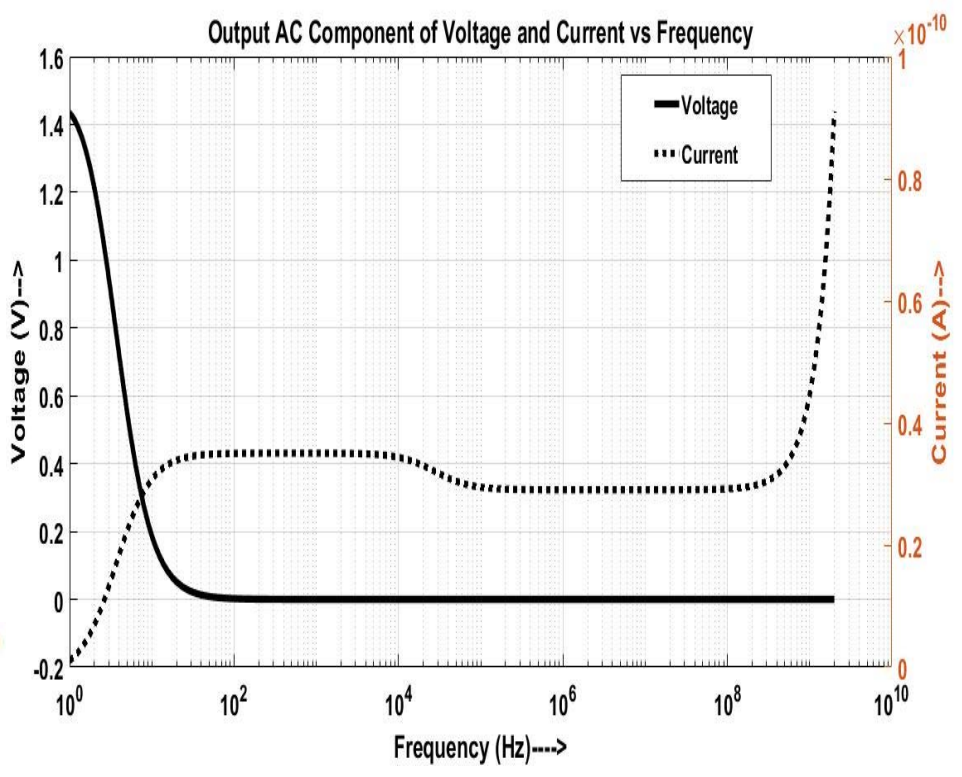

Figure 10: Output AC components of voltage and current vs frequency

The frequency response of the circuit is also simulated which clearly shows th at the circuit is suitable to be operated at a wideb and covering almost all p opularly available co mmercial bands. The output AC component of voltage and current of the design with respect to frequency is presented in Fig. 10. It is seen that over a wid e frequency range the AC co mponents of o utput is negligible which proves its suitability for wideband operations.

Also the temperature profile of the circuits are evaluated which clearly indicates the temperature stability in terms of both voltage and cu rrent. This is shown in Fig. 11. 


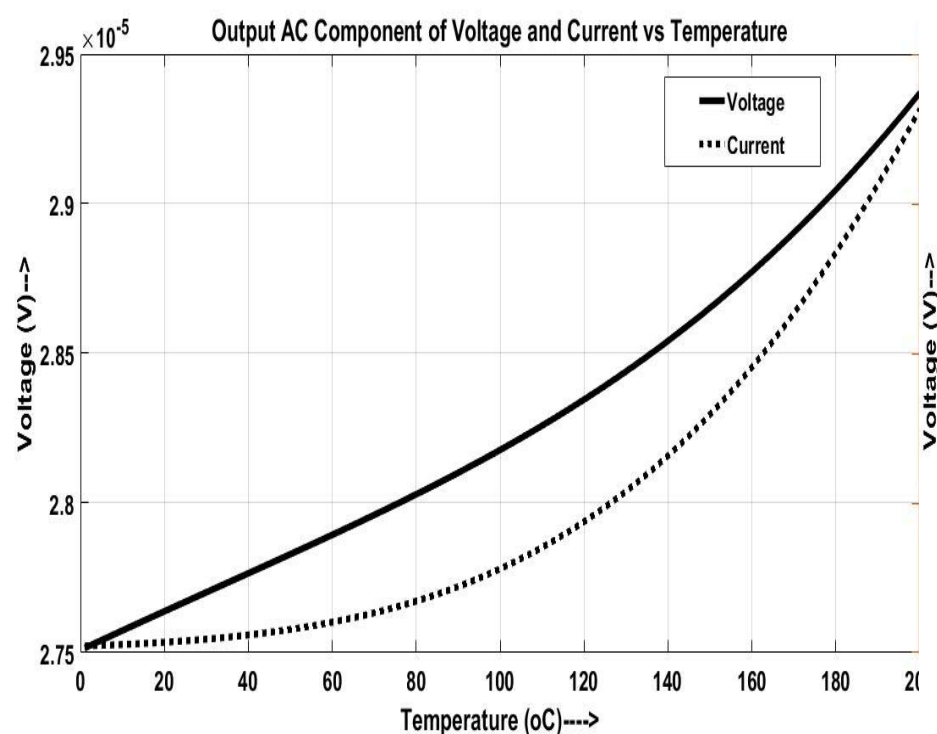

Figure 11: Output AC components of voltage and current vs Temperature

The variation of output AC co mponents of voltage and current with respect to input capacitance and output capacitance is also analyzed. Fig. 12 depicts the variation of output $\mathrm{AC}$ voltage and current with $\mathrm{C}_{\mathrm{in}}$, which indicates a minor change in both the parameter with increase $\mathrm{i} n \mathrm{C}_{\mathrm{in}}$. Also as the $\mathrm{C}$ out increases, the $\mathrm{AC}$ component of voltage falls whereas the AC co mponent of current marginally increases. This is presented in Fig. 13.

The output DC voltage and current with the change in the input power need $s$ to be analy sed and is presented in Fig. 14. This sho ws that both the voltage and current increases with increase in input power, which is expected as increase in input power would definitely increase the output power.

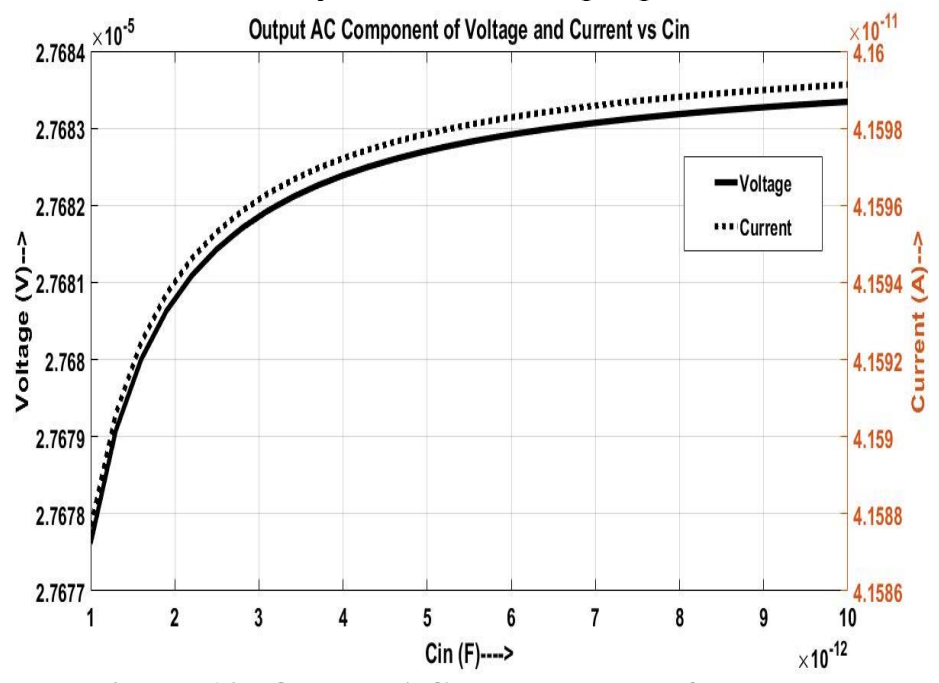

Figure 12: Output AC components of voltage and current vs $\mathbf{C}_{\text {in }}$

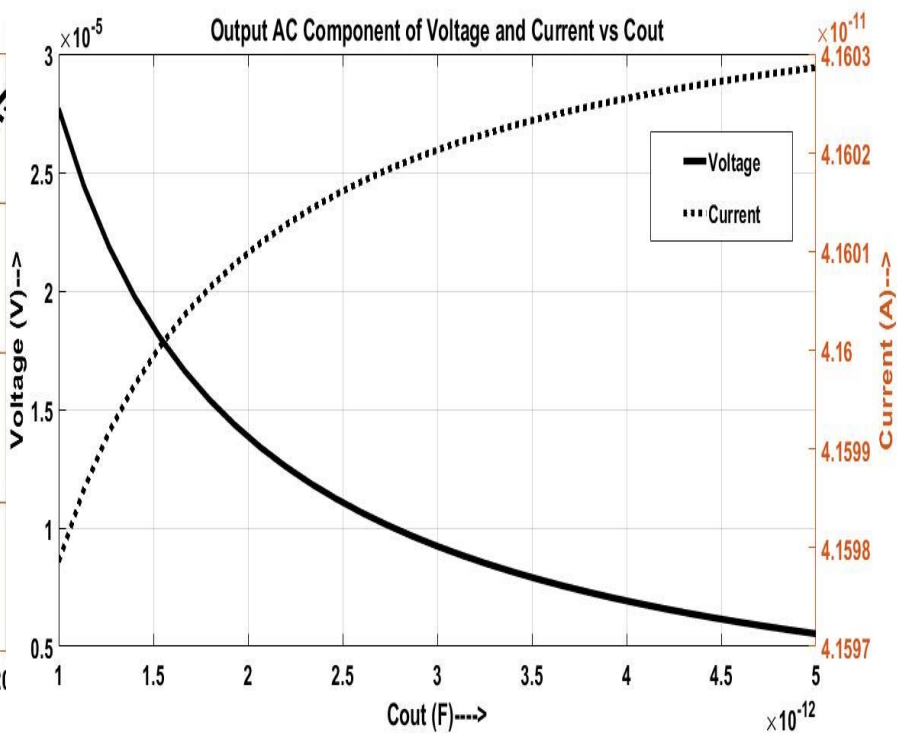

Figure 13: Output AC components of voltage and current vs $\mathbf{C}_{\text {out }}$

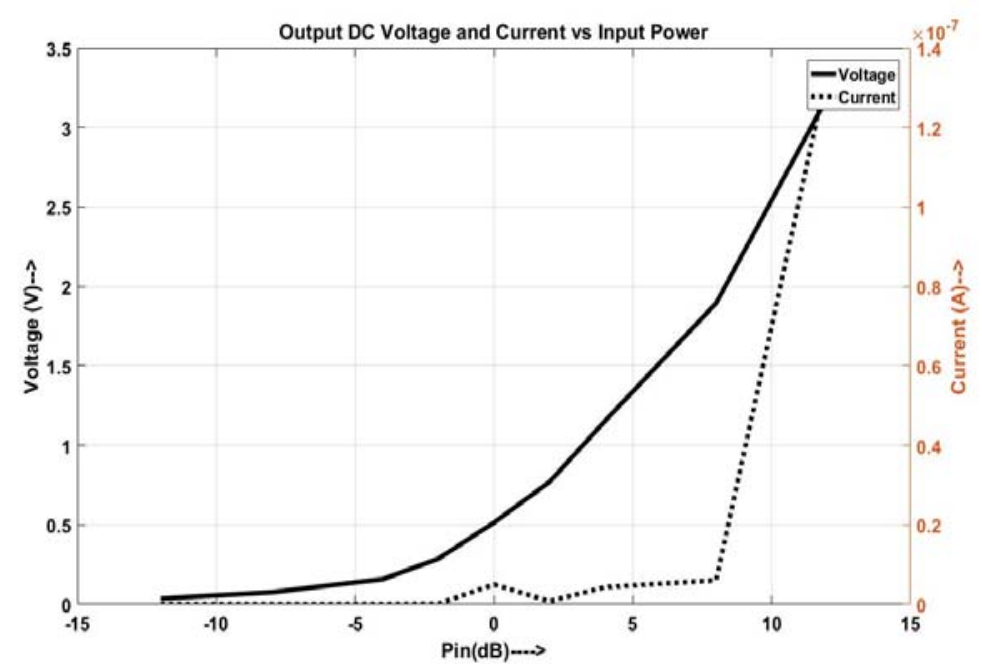

Figure 14: Output DC voltage and current vs $\mathbf{P}_{\text {in }}$ As the PCE of the circuit is the major and significant performance parameter, it is evaluated and presented in Fig. 15. T he PCE obtained are 90\% and 85\% at $2 \mathrm{db}$ and $-2 \mathrm{db}$ resp ectively. For higher input power, power gain is also observed. This clearly shows the efficacy of the design particularly at low input power applications. 


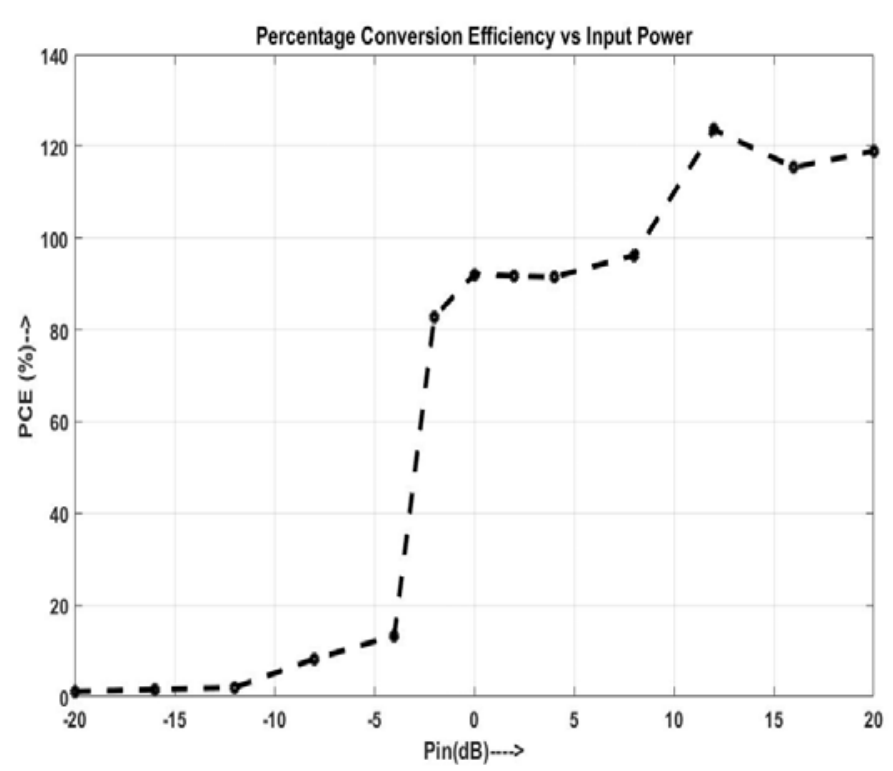

Figure 15: PCE vs $P_{\text {in }}$ for the circuit

The DPD at $-2 \mathrm{dBm}$ is plotted acro ss the output voltage and is shown in Fig. 16. The $i$ nstantaneous DPD is seen to ch ange with the value of output voltage

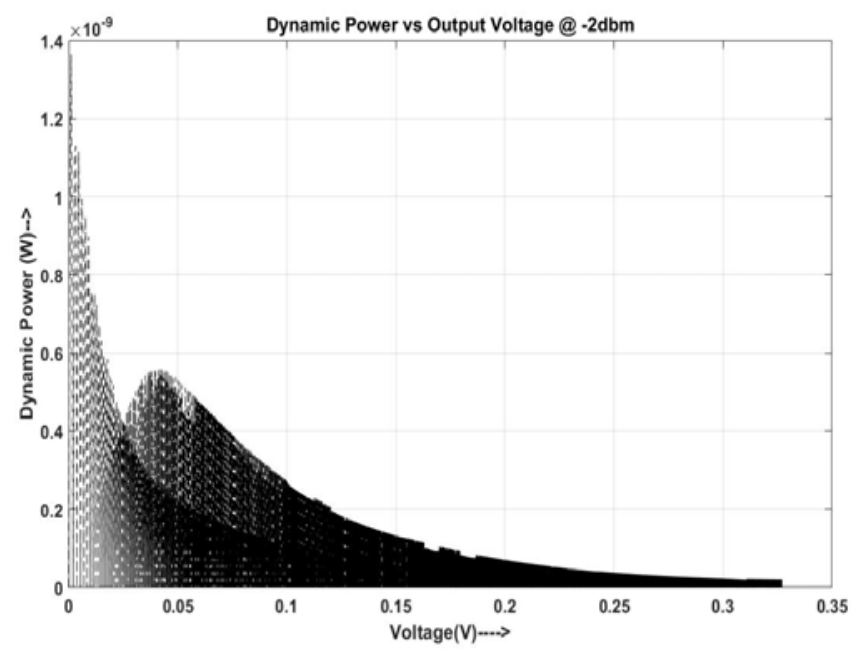

Figure 15: DPD vs output voltage at -2dbm

The key parameters of both the circuit are presented in Table 2. This sho ws that the d esign is capable to function at lower input power efficiently with significantly low power dissipation and zero leakag e power. Though the single stage output DC voltage is less but this can easily be enhan ced by having a cascaded structure. In[21] you will find so me other studies about CMOS.
Table 2: Key parameters of the circuit

\begin{tabular}{|c|c|c|}
\hline \multirow{2}{*}{ Parameters } & \multicolumn{2}{|c|}{ Input Power } \\
\cline { 2 - 3 } & $@ 2 \mathrm{~dB}$ & @-2dB \\
\hline O/P Voltage & $823 \mathrm{mV}$ & $286 \mathrm{mV}$ \\
\hline PCE & $90 \%$ & $85 \%$ \\
\hline DPD & $23.2 \mathrm{pW}$ & $6.25 \mathrm{pW}$ \\
\hline LP & 0 & 0 \\
& & \\
\hline
\end{tabular}

The results obtained are compared with a fe w recently reported works. This clearly depicts that the designs presented here provides the best single class efficiency with minimum number of MOS devices. This is shown in Table 3.

Table 3: Comparative Analysis with recent works

\begin{tabular}{|c|c|c|c|c|c|c|}
\hline \multirow[b]{2}{*}{ Work } & \multicolumn{6}{|c|}{ Comparison with the reported works } \\
\hline & Technology & Stage & $\begin{array}{c}\text { Frequency } \\
(\mathrm{MHz})\end{array}$ & $\begin{array}{l}\text { Input } \\
\text { Power } \\
(\mathrm{dbm})\end{array}$ & $\begin{array}{l}\text { Output } \\
\text { Voltage } \\
\text { (V) }\end{array}$ & $\begin{array}{l}\text { Max } \\
P C E \\
(\%)\end{array}$ \\
\hline [13] & Schottky Diode & 1 & 868 & 10 & - & 48 \\
\hline [14] & Schottky Diode & 1 & 900 & -10 & 0.66 & 40 \\
\hline [15] & Schottky Diode & 2 & 868 & -10 & 0.649 & 44 \\
\hline [16] & $\begin{array}{c}\text { Schottky Diode } \\
\text { in } 0.35 \mu \mathrm{m} \\
\text { CMOS }\end{array}$ & 5 & 900 & -14.8 & 1.5 & 36 \\
\hline [17] & TSMC $0.18 \mu \mathrm{m}$ & 8 & 925 & -21.2 & 0.78 & 43 \\
\hline [4] & $0.18 \mu \mathrm{m}$ CMOS & $\begin{array}{c}1, \\
\text { Diff }\end{array}$ & 953 & -12.5 & 0.62 & 67 \\
\hline [18] & $\begin{array}{l}\text { TSMC } 90 \mathrm{~nm} \\
\text { CMOS }\end{array}$ & $\begin{array}{c}5, \\
\text { Diff }\end{array}$ & 868 & -17 & 1.62 & 40 \\
\hline [19] & $65 \mathrm{~nm} \mathrm{CMOS}$ & 5 & 900 & 18 & 6 & 31 \\
\hline [7] & $65 \mathrm{~nm}$ CMOS & 2 & 953 & -15 & 0.402 & 56 \\
\hline [12] & $45 \mathrm{~nm}$ CMOS & 1 & 953 & -2 & 0.485 & 80 \\
\hline $\begin{array}{l}\text { This } \\
\text { work }\end{array}$ & $45 \mathrm{~nm}$ CMOS & 1 & 953,1800 & -2 & 0.286 & 85 \\
\hline
\end{tabular}

\section{Conclusion}

The 3-transistor rectifier presented here is a improved structure im plemented with threshold voltage compensation technique, which can al so be viewed as a simplification to the TG based design in [12]. This rectifier is also dem onstrated to be suitable over a wide band of frequenci es spanning almost all commercially available frequency bands. The PCEs achieved at $2 \mathrm{db}$ and $-2 \mathrm{~dB}$ are $90 \%$ and $85 \%$ respectively. By comparing with the recently reported works, it can be stated to be sufficiently 
higher at low input power. This proves the efficacy of the design for low power RF en ergy harvesting and makes a potential candidate for facilitating selfsustainability to a co mmunication system, particularly as part of a green co mmunication setup. As the circuit works success fully with only 3transistors and only few components, hence the area efficiency can be said to be another striking feature of the design. This also makes the design a design cost-effective. The DPD and LP are al so evaluated and presented in the Table 2, which sh ows that the circuit provides a signifi cantly low DPD and zero LP. A significantly low D PD means the circuit is feasible to be implemented in a power a ware set-up. Again a zero LP indicates almost zero power loss. Finally, the design can be said to be significant in considerations to the fo llowing parameters viz higher PCE at a low inp ut power, wide frequency range compatibility, only 3 numbers of transistors, very low power dissipation and zero leakage power. This proposed concept of the design may be extended to make the sy stem capable provide high PCE at even lower input power. The multistage implementation of the circuit can provide a higher output voltage, which is another required dimension to be explored.

\section{References:}

[1] S. Ulukus, A. Yener, E. Erkip, O. Simeone, M. Zorzi, P. Grover, and K. Huang, 'Energy Harvesting Wireless Communications: A Review of Recent Advances', IEEE Journal of Selected Areas in Comm., vol.33, no.3, pp-360-381, 2015

[2] S. Sudevalayam and P. Kulkarni., "Energy harvesting sensor nodes: Survey and implications", IEEE Comm. Surveys Tutorials, vol.13, no. 3, pp443-461,2011.

[3] J. Rabaey, M. J. A mmer, J. L. Silva, D. Patel, and S. Roundy. "PicoRadio Supports Ad Hoc UltraLow Power Wireless Networking", IEEE Computer, vol.33, pp-42-48, 2000.

[4]K. Kotani, A. Sasaki and T. Ito, "High-Efficiency Differential-Drive CMOS Rectifier for UHF RFIDs", IEEE Jornal of Solid-State Circuits, vol. 44, no.11, 2009.

[5]M. L Matia et al, “ A comparision of HighEfficiency UHF RFID Rectifier Using Internal Voltage Compensation and Zero-Threshold-Voltage MOSFETs", 2014 IEEE 5th Lati n American Symposium on Circuits and Systems, 2014.

[6] H. Lin, H. Cao, Z. Chen, W. C. Chan, W. K. Lee and M. Zhang, " Leakage Current Elimination for
Dickson Charge Pump with a Linear Regulator", ELSEVIER Microelectronics Journal, vol. 64, pp. 29-34, 2017.

[7] M. Tagh dosi, L. Albasha, N. A. Quadir, Y. A. Rahama and N. Qaddoumi, "High Efficiency Energy Harvesters in $65 \mathrm{~nm}$ Process for Autonomous IoT Sensor Applications", IEEE Access, vol. 6, pp2397-2408, 2018.

[8] M. M. Mohamed et al., "High-Efficiency CMOS RF-to-DC Rectifier Based on Dynamic Threshold Reduction Technique for Wireless Charging Applications", IEEE Access, vol. 6, Pp-4682646831, 2018.

[9] M. M. Mansour and H . Kanaya, "High-Efficient Broadband CPW RF Rectifier for Wireless Energy Harvesting", IEEE Microwave and Wireless Components Letters, vol: 29 , no: 4 , pp-288-290, 2019.

[10] S. Yuh Lee, Z. Xian Liao and C. Hung Lee, "Energy-Harvesting Circuits With a HighEfficiencyRectifier and a Low Temperature Coefficient Bandgap Voltage Reference", IEEE Transactions On $\mathrm{V}$ ery Large $\mathrm{Sc}$ ale Integration (VLSI) Systems, vol. 27, no. 8, pp-1760-1767, 2019.

[11] T. Oh, O. Hassan, S. Shamsir and S. K. I slam, "Low-Power RF Energy Harvester Circuit Design for Wearable Medical Applications", United States National Committee of URSI National Radio Science Meeting (USNC-URSI NRSM), USA, 2019.

[12] M. P. Sarma, K. K. Sarma, N. E Mastorakis, "Design of a TG Based High Frequency Rectifier at $45 \mathrm{~nm}$ for RF Energy Harvesting Application", 2nd IEEE European Conference on Electrical Engineering and Computer Science (EECS), pp-52523, Athens, Greece, 20-22 Dec. 2018.

[13] D. Allane, G. A. Vera, Y. Duroc, R. Touham i, and S. Tedjini, " Harmonic Power Harvesting System for Passive RFID Sensor Tags", IEEE Transaction on Microwave Theory Technology, vol. 64, no. 7, pp. 2347-2356, Jul. 2016.

[14] D. Masotti, A. Costanzo, P. Francia, M. Filippi, and A. Romani, " A Load modulated rectifier for RF Micro-power Harvesting with Start-up Strategies', IEEE Transaction on Microwave Theory

Technology, vol. 62, n o. 4, pp. 9 94-1004, Apr. 2014.

[15] D. A ssimonis, S.-N. Da skalakis, and A. Bletsas, "Sensitive and Efficient RF Harvesting Supply for Batteryless Backscatter Sensor Networks' IEEE Transaction on Microwave Theory Technology, vol. 64 , no. 4, pp. $1327-1338$, Apr. 2016 
[16] J. W. Lee and B. Lee, “ A Long-range UHFband Passive RFID Tag IC Based on High-Q Design Approach" IEEE Transactions on Industrial Electronics, vol. 56, no. 7, pp. 2308-2316, Jul. 2009.

[17] C.-Y. Yao and W.-C. Hsia, "A-21.2 - $d B m$ Dual-channel UHF Passive CMOS RFID Tag Design", IEEE Transaction on Circuits and Sy stems I, Reg. Papers, vol. 6 1, no. 4, pp. 1269-1279, Apr. 2014

[18] M. Stoopm an, S. Key rouz, H. J . Visser, K. Philips, and W. A. Serdijn, "Co-design of a CMOS Rectifier and Small Loop Antenna for Highly Sensitive RF Energy Harvesters," IEEE Journal on Solid-State Circuits, vol. 49, no. 3,pp. 622-634, Mar. 2014

[19] C.-H. T sai, I.-N. Liao, C. Pakasiri, H.-C. Pan, and Y.-J. Wang, " A Wideband $20 \mathrm{~mW}$ UHF Rectifier in CMOS", IEEE Microwave and Wireless Component Letters.,vol. 25, no. 6, pp. 388-390, Jun. 2015.

[20] H. Kim and I. Kwon, "Design of HighEfficiency CMOS Rectifier with Low Reverse Leakage for RF Energy Harvesting", Electronics Letters, vol. 55 No. 8 pp. 446-448, 2019.

[21] Yogita Gajare, Arti Khaparde, Design and Simulation of First Order One Bit Sigma Delta ADC in 180nm CMOS Technology WSEAS Transactions on Electronics, pp.1-7, Vol.9, 2018 